\title{
Beyond dialogue and antagonism: a Bakhtinian perspective on the controversy in political theory
}

\author{
Leszek Koczanowicz
}

Published online: 19 June 2011

(C) The Author(s) 2011. This article is published with open access at Springerlink.com

\begin{abstract}
The aim of the article is to show that the contradiction between dialogue and antagonism can be overcome with the help of the idea of dialogue as developed by the Russian thinker Mikhail Bakhtin. The lack of such theory led to the rejection of liberalism or to the introduction of dialogical principle into the body of liberal politics. It was Jürgen Habermas who first understood the necessity of dialogical consensus as the basis of liberal democracy. On the other hand, Ernesto Laclau and Chantal Mouffe developed the concept of agonistic democracy, claiming that conflict is inevitable in liberal democracy because consensual relations cannot harmonize contradictory political identities. The second part of the article is the elaboration of Bakhtin's theory of dialogue and its relevance for political theory. The main point is that dialogue leads to better understanding but not necessarily to consensus. If this is so, then both conceptions of the political are moments in never-ending dialogical relations. The significance of Bakhtin's idea of dialogue for political theory consists thus in the recognition of the inevitable dialogical nature of society. However, this dialogical concept also has a normative character. Society has to find a balance between two extremes: excessive dialogue, which leads to anarchy, and the lack of dialogue, which leads to totalitarianism.
\end{abstract}

Keywords Democracy·Hegemony $\cdot$ Liberalism $\cdot$ Bakhtin $\cdot$ The political

Dialogue and antagonism seem to constitute a pair of opposite concepts and in such a way are they treated in contemporary political theories. The dialogical perspective assumes that for all political arguments one can find a resolution that will satisfy all parties involved in a controversy. The antagonistic perspective takes for granted that irreducible antagonism is a constitutive part of each society. Therefore, the only possibility for a society to exist is to suppress antagonism by imposing on that

L. Koczanowicz $(\bowtie)$

The Warsaw School of Social Sciences and Humanities, Wroclaw Faculty, ul. Grunwaldzka 96, 50-357 Wroclaw, Poland

e-mail: Leszek@post.pl 
society a particular point of view. This entails using force, either symbolic or real. My aim in this article is to show that it is possible to envisage a democratic association, which while dialogical allows at the same time for some kind of antagonistic perspective. For this purpose I would like to employ a dialogical concept developed by Mikhail Bakhtin, who is one of the fundamental figures in cultural studies but apparently has been comparatively ignored in political theory. I think that his idea of dialogue can be of use for building a non-consensual notion of democracy. Democracy then is seen as a complicated set of conversations that do not necessarily lead to a consensus but could promote better understanding between all participants in the political struggle.

Before I start my argument about non-consensual democracy I intend to trace the complicated history of the constitution of both perspectives, dialogical and antagonistic. It is clear that they emerge from two independent sources. On the one hand, both are responses to the challenges of the complexity of social and political life in the period of modernity. Freedom and the autonomy of the individual pose the question of social order in a fragmented and shattered world. The basic categories of power and human relations had to be redefined. As Charles Taylor writes, it was necessary to create a new "moral order," which would be a prosthesis for the lost feeling of community (Taylor 2007, 18-22). Here we touch upon the second aspect of the constitution of the two perspectives. It refers rather to the nature of power, human nature, and human relations rather than to politics. The moral order of modernity consists of individualism, which means, among other things, that society is established for the good of the individual, and political society enables individuals' mutual advantages. This subordination of political society to the individual is expressed in the language of rights, of which liberty is the most important. Eventually, it also becomes of importance that rights, liberties, and mutual advantages are distributed equally; this principle takes different forms, but all of them mean the rejection of a hierarchical order (Taylor 2007, 18-22).

Thus in modernity the concepts of dialogue and antagonism seem to be inevitably connected with another pair: that of liberalism and anti-liberalism. Liberalism proposes the notion of an autonomous and free individual who is directed by rational motives. This individual rationality can always be translated into the collective rationality that leads to a compromise in the public sphere. However, the basic problem for all versions of liberalism, which is left unsolved, is the shift from an individual rationality to a collective rationality. For a collective action to work, individuals have to coordinate their actions and harmonize their views. However such coordination assumes a priori the limitation of freedom and autonomy of individuals, which threatens the main principles of liberalism. This contradiction is described by Pierre Manent as the relation between modern man and law that should be a locus of political universality and shared action of citizens. He writes: "... modern man as modern, both flees from and seeks out law. He flees the law that is given to him and seeks the law he gives himself' (Manent 1998, 204).

This contradiction can be bypassed in two ways. Firstly, we can hypostatize the public reason and take individual rationality as an expression of such "higher rationality." Secondly, we can presuppose that there are values aprioristic to individual actions. Both solutions have appeared in various incarnations from the social a priori of the Neo-Kantians through the common good of communitarians, to 
John Rawls's public reason. However, all these efforts could not eliminate this flaw from liberal philosophy, and in fact it became the point of departure for the critique of the political strategy of liberals. This critique concerns mainly the inability of liberalism to account for the ways in which collective identities are constructed and their role in the political. The opponents of liberalism from the right claim that liberal political theory neglects the significance of hostility between different groups as a main factor of political life. Carl Schmitt's concept of the enemy/friend distinction as the constitutive factor of the political is the best example of this analysis. Leftist thinkers, and Antonio Gramsci's conception is the most significant for my reasoning, show that the most important factor for the political is hegemony exerted by a specific social group over whole society.

The two lines of critique mentioned above forced contemporary social theoreticians to think over again the fundamentals of liberalism. This revision goes in two opposite directions: to introduce a dialogical perspective into the body of liberal theory, and to show that a certain version of antagonism is inherited by liberal society. The first line originated in claims by American pragmatists that one can always find a mechanism that enables individuals to find a common perspective and that such a perspective is a characteristic of the social bond. George Herbert Mead shows that taking the role of the other is a necessary condition of the socialization of man. Therefore the process of socialization itself contains a mechanism for harmonizing the perspectives of individuals acting together. However it was Jürgen Habermas who realized that a certain concept of dialogue is indispensable for liberal thought. Accepting the principles of pragmatism, he presents the idea of communication as a social action where every member of social interaction is directed to achieving an understanding with others. The possibility of such a dialogue is embedded in language itself. The communicative action is a basis for such human interactions which, embedded in democracy, would organize political relations as a rational dialogue leading to a rational consensus. The "ideal communicative situation" postulated by Habermas is of course of a normative character but it is an inevitable point of reference for all actual procedures of achieving a consensus existing in democratic societies. Therefore Habermas's theory has a double descriptive and normative dimension. It is descriptive as it shows a potentiality existing in every communication and it is normative as it shows that the activation of this potentiality needs a democratic procedure.

Habermas shows that the introduction of the dialogical principle is a necessary supplement for the political theory of liberalism. He at the same time insists that dialogue is not contingent in the body of statements constituting liberal theory; on the contrary, it is located in the very center of every social bond, and therefore it has be taken into account by liberalism as a philosophy describing society as an association of free individuals. The procedures of reciprocal understanding are obligatory for the existence of this association. However in real societies they cannot be fully realized as procedures constituting the political. They are suppressed almost entirely in non-democratic societies but even in empirical procedures of democracy they can hardly be fulfilled, being always a normative-utopian point of reference. Habermas puts this relationship between self, intersubjectivity, and politics in the following way: "The structures of reason to which Adorno merely alludes first become accessible to analysis when the idea of reconciliation and freedom are 
deciphered as codes for a form of intersubjectivity, however utopian it may be, that makes possible a mutual and constraint-free understanding among individuals in their dealings with one another, as well as the identity of individuals who come to compulsion-free understanding with themselves - sociation without repression. This means, on the one hand, a change of paradigm within action theory: from goal directed to communicative action, and, on the other hand, a change of strategy in an effort to reconstruct the modern concept of rationality that becomes possible with the decentration of our understanding of the world" (Habermas 1991, 391-392).

In the second line the concept of dialogue is rejected because of the claim that all societies, democratic included, are the terrain of inevitable internal struggle. In contrast to the critics of liberalism from the left and the right, the representatives of antagonism theory do not think that the necessity for struggle can mean the failure of liberal democracy. As Claude Lefort states, if we are aware of these setbacks of democracy then we can protect it from the temptations of totalitarianism. Democracy is a system of constant internal struggle because it differs from other political forms in that it is organized around "empty space." Thus the fight for a valid definition of "people" is built into this system. Antagonism is hence of the essence of democracy while it is at the same time a threat for democratic society and the source of its strength. Democracy has to define itself all the time as it is a system that needs constant change. On the other hand, it is also in constant danger of falling into totalitarianism where empty space is filled by a clear definition of "the people." Bernard Flynn defines these relations in Lefort as follows: "Within a democracy the source of legitimate power is 'the people' but who is to speak in the name of the people? According to Lefort, political life in a modern democracy is a continual debate on just this question. No one claims to be authorized a priori to speak in the people's name; each person's claim must be discursively validated and every claim is always subject to challenge. The legitimate spokesperson for the people cannot be established with certainty; it is always 'up for grabs' and as such it engenders an anxiety. The political anxiety which is endemic to democracy is experienced most intensely in times of crisis; it has as its 'object' the possibility that the symbolically empty space will become really empty, which is to say, no one will be able to establish legitimacy and this would mean that the symbolic place of power would fall into real" (Flynn 2005, xxv).

Some of Lefort's insights have been taken up by Chantal Mouffe and Ernesto Laclau, who have developed their own highly original project of understanding society as inevitably torn apart by contradictions and at the same time organized by hegemonic relations. As Chantal Mouffe writes in a book devoted to Carl Schmitt's challenges to liberal democracy, "Democratic consensus can be envisaged only as a conflictual consensus. Democratic debate is not a deliberation aimed at reaching the one rational solution to be accepted by all, but a confrontation among adversaries. Indeed, the category of adversary is crucial to redefining liberal democracy in a way that does not negate the political in its antagonistic dimension. The adversary is in a certain sense an enemy, but a legitimate enemy with whom there exists a common ground. Adversaries fight against each other, but they do not put into question the legitimacy of their respective positions.... Conceived in such a way, liberaldemocratic politics can be seen as a consistent and never fully achieved enterprise to diffuse $[s i c]$ the antagonistic potential present in human relations. By creating the 
conditions for possible conflicts to take the form of confrontations among adversaries (agonism), it attempts to avoid a frontal struggle between enemies (antagonism)" (Mouffe 1999, 4).

Such a perspective is of course radically different from that of Habermas. In his case we have a rational consensus achieved in dialogue (communicative actions), which has to lead to mutual understanding if there exist no factors distorting communication. Collective identities emerge from individual identities in this rational dialogue. Chantal Mouffe and Ernesto Laclau envisage the constitution of collective identities through the complex mechanism of the integration of chains of equivalence and subjective positions. Therefore, as Critchley and Marchart write, "... identity is no longer conceived as a mere effect of structural construction, but is the outcome of a process of identification triggered by an originary 'lack of identity' named 'the subject"' (Critchley and Marchart 2004, 6). Collective identities never have a rational character; they are an effect of contingent social and political conditions. Politics, or more precisely speaking the political, is always, contrary to Habermas, a field of oppositional interests and unpredictable decisions. However, as Stefan Rummens points out, “...Mouffe's agonistic model of politics is marred by some crucial but persistent ambiguities which result from an unresolved tension between the alleged hegemonic nature of the democratic struggle on the one hand and the presence of a common symbolic framework on the other" (Rummens 2009, 378).

Democratic politics thus needs to find a place for some kind of consensus that could encompass its agonistic tension, but how is it possible to have antagonism and consensus at the same time? Is the contradiction between these two positions inevitable? In my opinion, they can be harmonized or at least treated as complementary, if we accept a different conception of dialogue than that of Habermas. He does not refer to any of the dialogical theories developed in so-called dialogical philosophy, with the important exception of G.H. Mead, who, as I have argued elsewhere, is interpreted in such a way that his dialogical attitude disappears (Koczanowicz 1999). No wonder that we see more and more attempts to link Habermas's theory to the dialogical tradition, and first of all to the thought of M.M. Bakhtin. This task is nevertheless neither easy nor trivial. These theories seem to be incommensurate. Habermas builds his theory consciously as a foundation for democracy, while Bakhtin concentrates on literature, language, and dialogue itself.

One of the possibilities is to compare both thinkers on ethical grounds, and to show that a Bakhtinian approach can modify the universality of the transcendental pragmatic ethics. For instance, Greg Nielsen writes: "It is not difficult to imagine how close Bakhtin's approach comes to universal pragmatics in that he would agree that a claim of sincerity coordinates the construction of the utterance and the claims of truth and validity are in fact part of almost any dialogue. On the other hand, for Bakhtin, the open ethical event where questions of 'oughtness' are worked out has no universal grounding. What is universal about the utterance is its varying degree of answerability. Even monological or strategic forms of utterances, those that make no space for transcultural hybrids, and that in extreme cases seek no response at all from the listener of the same lifeworld but presume the last word, are still answerable" (Nielsen 1995, 827). Such modified universal ethics can be used for analyses of political problems and to show that their solution needs something more than merely finding a common denominator for different views. 
However, I would like to offer another way of proceeding, not contradictory to the ethical approach but supplementing it. I focus here on the question of how the dialogical approach can constitute the public sphere and whether it can serve to harmonize the two contradictory perspectives I outlined above. The issues at stake are two crucial problems in constructing a democratic society: the possibility of dialogue within such a society and the rules for forming collective identities. I show that Bakhtin's idea of dialogue can be involved in those two tasks. Dialogue is a vehicle for forming a common perspective encompassing opinions of different individuals and therefore a mode for forming collective identities but it can also provide a framework for mutual understanding between groups and individuals.

Ken Hirschkop, in the Introduction to his book on the significance of Bakhtin's ideas for politics, emphasizes that two interpretations of the idea of dialogue make it in fact difficult to use this concept in political theory. The first of them identifies dialogue with dialogue between man and God, and hence dialogue becomes a universal and mystical concept. In the second interpretation, dialogue refers to everyday events, which elude any kind of universality. As a consequence, as Hirschkop writes, "Affirmation that dialogue is hidden in the recesses of every utterance amounts to little more than wish-fulfillment in pseudo-philosophical form when the substance of that dialogue turns out to be the unfulfilled norms of American liberalism. While the religious-existential aura which envelops dialogue in Russia would have to be dispersed for anything worldlier to emerge, in the West the problem is nearly the reverse: dialogue is too worldly or, in the philosophical sense of the term, 'positive,' a simple and uncritical reflection of institutionalized norms" (Hirschkop 1999, 9-10).

This protest against instrumentalization of dialogue is right, as it shows that dialogue is not only a consequence of the internal structure of language but is a value in itself that one should long for. In other words, dialogue is a feature of language (or strictly speaking of language utterance) and dialogue is also a feature of communication. In the first meaning we can say that each utterance has a more or less implicit dialogical character: "Dialogic relationships, therefore, are extralinguistic. But at the same time they must not be separated from the realm of discourse, that is from language as a concrete integral phenomenon. Language lives only in the dialogic interaction of those who make use of it. Dialogic interaction is indeed the authentic sphere where language lives. The entire life of language, in any area of its use (in everyday life, in business, scholarship, art, and so forth), is permeated with dialogic relationship" (Bakhtin 1993a, 183). This idea is even more strongly stated in Freudianism (Vološinov 1976). A therapist and a patient create a social event in which both sides have their particular interests. In general, Bakhtin writes, "Not a single instance of verbal utterance can be reckoned exclusively to its utterer's account. Every utterance is the product of the interaction between speakers and the product of the broader context of the whole complex social situation in which the utterance emerges" (Vološinov 1976, 79). The dialogical character of language is a reflection of a complex, social situation of communication in which misunderstandings and conflicts are as common as understanding and reconciliation.

Thus language is a dialogical phenomenon, but that does not mean that in each of its appearances the possibility of a consensus emerges. To the contrary, this social, intersubjective existence of language makes it the field of constant struggle for the 
domination of certain meanings. Contradictions in psychic life are consequences of tensions in the social world; for example, unconsciousness is "unofficial consciousness" which is rejected by the "official consciousness" of an individual and for this reason cannot be represented in its conscious psychic life. However, as the commentator notes, Bakhtin himself never developed these intuitions in psychology; he turned to literature and employed the term "unofficial culture" brilliantly in his Rabelais book (Makhlin 1993).

It seems to me that this perspective is different from that of Habermas, although both would agree that dialogue is a necessary condition of every language encounter between human beings. However, Habermas proposes the strong claim that the dialogical character of language is the consequence of its internal structure, of the logic imposed by the procedures of communication. Rationality of communication, its orientation towards reciprocal understanding, has to lead to a consensus if, of course, the influence of violence or other forms of coercions are eliminated: “...communicative reason does not simply encounter ready-made subjects and systems; rather, it takes part in structuring what is to be preserved. The utopian perspective of reconciliation and freedom is ingrained in the conditions for the communicative sociation of individuals; it is built into the linguistic mechanism of the reproduction of the species" (Habermas 1991, 398).

For Bakhtin the dialogical approach of language is very different from that of logic: "... logical and semantically referential relationships, in order to become dialogic, must be embodied, that is, they must enter another sphere of existence: they must become discourse, that is, an utterance, and receive an author, that is a creator of the given utterance whose position is expressed" (Bakhtin 1993a, 184). Dialogical relations are always intersubjective and as a consequence they convey to dialogue itself a tension, which can appear between different subjects. However, dialogical relation is also a basis for agreement to the extent that it is at same time a basis for mutual understanding. "With explanation there is only one consciousness, one subject; with comprehension there are two consciousnesses and two subjects. There can be no dialogic relation with an object, and therefore explanation has no dialogic aspects.... Understanding is always dialogic to some degree" (Bakhtin 1994, 111). What is of special importance for Bakhtin is that "primary ethics" is always concrete. It is, in the words of his commentator, "co-existential ethics": "Bakhtin's philosophy of the act radically departs from traditional notions of ethics, both material and formal. Insofar as it deals with the architectonics of co-existence, that is, that level of human sociality which underlines and informs the sphere of values and norms, the philosophy of the act can be described as co-existential ethics prior to ethics in any traditional sense. My concrete, active relatedness to acting others makes the creation and enactment of values and norms possible in the first place" (Eskin 2000, 75). This idea of co-existential ethics has far reaching consequences for political theory, as dialogue is simultaneously language-bound, and as dialogical relation it is an existential relation between acting human beings. In his early works Bakhtin shows that each individual is involved in the relationships with others and that this involvement is a necessary condition for moral philosophy. "It is this concrete architectonic of the actual world of the performed act that moral philosophy has to describe, that is, not the abstract scheme but the concrete plan or design of the world of unitary and once-occurent act or deed, the basic concrete moments of its 
construction and their mutual disposition. These basic moments are I-for-myself, the other-for-me, and I-for-the-other... All spatial-temporal values, all sense-content values are drawn and concentrated around these central emotional-volitional moments: I, the other, and I-for-the-other" (Bakhtin 1993b, 54). Bakhtin describes the mutual relationships between I and other as a set of passages from one to another. We perceive an event from our own perspective, we can adopt the perspective of the other and enrich our own, but these two consciousnesses never fuse. An individual is always a unique entity but it cannot exist in separation from the other and both moments of this existential situation of the human being are constitutive for dialogue (Koczanowicz 2000). The idea of inevitability of communication with the other for construction of our own identity is recurrent throughout Bakhtin's work. In the notes to the Dostoevsky book he writes: "A person has no internal sovereign territory, he is wholly and always on the boundary; looking inside himself, he looks into the eyes of another or with the eyes of another" (Bakhtin 1993a, 287).

A problem arises, however, whether this inevitably dialogical nature of the self can be translated into the political categories of constituting of public sphere in dialogue. Each individual needs a dialogue, but what does this mean for the constitution of the political? To answer this question we have in turn to show how in dialogue we can arrive at a consensus, whether an agreement is inscribed in dialogue itself or a consensus is external to dialogue itself, and depends on the good will of the participants, their existential situation, or other extraneous factors. If we analyze Bakhtin's point of view we at the same time touch upon what is so clearly stated in Hegemony and Socialist Strategy, namely the discursive concept of politics. This perspective is similar to that of Bakhtin as in both cases text is prior to reality and the relation between texts is a basis for social analysis. The difference is, however, that Mouffe and Laclau, as the heirs of the structuralist orientation, are convinced that the text is entirely independent of the social reality; for them power relations refer to hegemony that always has a linguistic character and enables a particular group to fill empty signifiers with its particular meanings. They write: "Our analysis rejects the distinction between discursive and non-discursive practices. It affirms: a) that every object is constituted as an object of discourse, insofar as no object is given outside every discursive condition of emergence; and b) that any distinction between what are usually called the linguistic and behavioural aspects of a social practice, is either an incorrect distinction or ought to find its place as a differentiation within the social production of meaning, which is structured under the form of discursive totalities" (Laclau and Mouffe 1985, 107).

Bakhtin seems to accept the thesis that text refers to a relations between different subjects. "The event of the life of the text, that is, its true essence, always develops on the boundary between two consciousnesses, two subjects. The transcription of thinking in the human sciences is always the transcription of a special kind of dialogue: the complex interrelations between the text ... and the created, framing context.... This is the meeting of two texts - of the ready-made and the reactive text being created - and, consequently, the meeting of two subjects and two authors. The text is not a thing, and therefore the second consciousness, the consciousness of the perceiver, can in no way be eliminated or neutralized" (Bakhtin 1994, 106-107). It is not clear how we can define "the subject" and "the perceiver" in Bakhtin, and what their consciousness is. Perhaps one can risk saying that these categories are 
underlined by complex historical, social, and cultural relations although by no means can the subject be reduced to them. Such an interpretation would allow us to make a link between Bakhtin's approach and the theoretical point in Post-Marxist theory that is emphasized by Anne Smith as a necessity, to supplement Lacanian theory by a Gramscian approach to historicity. She writes, "Competing articulations never work on a signifier as if it were blank space; every floating signifier has some meaningalbeit one that is always open to subversive recitation - insofar as it bears the fading traces of past articulations. The effectiveness of a political discourse, in other words, is not merely a question of its formal characteristics" (Smith 1998, 82).

Bakhtin would agree that dialogue always has two sides: on the one hand, it is a formal characteristic of language; on the other hand, it is always an expression of living social relations. As it is stated in Philosophy of the Act: "Two words confront each other, two words that have absolutely no communication with each other and are mutually impervious: the world of culture and the world of life, the only world in which we create, cognize, contemplate, live our lives or die or-the world in which the acts of our activity are objectified and the world in which these acts actually proceed and are actually accomplished once and only once" (Bakhtin 1993b, 2). This dual characteristic of every activity (using Bakhtin's expression it is like "two-faced Janus") introduces contradiction into social relations. On the one hand, they are objectified and subordinated to various social norms and on the other hand, they are an immediate encounter between individuals. These two characteristics of the social as Bakhtin says "confront each other" and this tension has far reaching consequences for social theory as language falls in the first category whereas dialogue is an embodiment of the second one. For that reason, as Holquist and Clark argue, "A dialogue in Bakhtin's system is a datum from experience that can serve as an economical paradigm for a theory encompassing more global dimensions. In an exchange between two speaking subjects, what each says to the other is difficult to describe in terms of language alone. The talk is segmented not only by words and sentences but also by protocols that determine who is talking. The different ways in which speakers indicate appropriate points for others to respond are enormously varied, depending on the topic, the speakers, and the context of the utterance. But the relations between utterances are always conditioned by the potential response of another. Thus, these relations are part of communication and cannot be adequately dealt with in terms of the language system alone" (Clark and Holquist 1984, 217).

In this context I place the category of dialogic relations, which are broader than dialogue itself because they “... are always present even among profoundly monologic speech works" (Bakhtin 1994, 125). The dialogical relation, even though it contains antagonistic tension, cannot be reduced to it. "Agreement is very rich in varieties and shadows. Two utterances that are identical in all respects ... if they are really two utterances belonging to different voices and not one, are linked by dialogic relations of agreement" (Bakhtin 1994, 125).

The dialectics of agreement and disagreement of dialogical utterances can be included in the problem of understanding, which for Bakhtin always has a dialogical character. "Understanding itself enters as a dialogic element in the dialogic system and somehow changes its total sense. The person who understands inevitably becomes a third party in the dialogue ... but the dialogic position of this third party is a quite special one.... But in addition to this addressee (the second party), the 
author of the utterance ... presupposes a higher superaddressee (third), whose absolutely just responsive understanding is presumed, either in some metaphysical distance or in distant historical time" (Bakhtin 1994, 126). Such a configuration of dialogue assures that there is no privileged position in it that could be an ultimate instance of understanding. The reference to the superaddressee does not close the discussion; on the contrary, such a reference becomes the subsequent step in a neverending dialogue. "Being heard as such is a dialogic relation. The word wants to be heard, understood, responded to, and again to respond to the response, and so forth ad infinitum. It enters into a dialogue that does not have a semantic end..." (Bakhtin 1994, 127). If we compare the idea of superaddressee with Habermas's idea of ideal community of communication, then we can see the significant differences between Bakhtin's and Habermas's positions. In the introductory parts of the second volume of the Theory of Communicative Action, Habermas claims that the ideas of freedom and community outlined merely in a negative way by Adorno can be developed positively on the basis of Mead's concept of action. The final result of such a theory is the project of an ideal community of communication-a "utopia" that "serves to reconstruct an undamaged intersubjectivity that allows both for unconstrained mutual understanding among individuals and for the identities of individuals who come to an unconstrained understanding with themselves" (Habermas 1987, 2). It seems that Bakhtin does not have such a transcendental construction for his idea of dialogue. The superaddressee is not the mark of a transcendental or quasi-transcendental horizon of communication. On the contrary, it represents a horizon of dialogue from the point of view of somebody who is engaged in the dialogue, but it is not an "objective" point of reference for understanding.

On the other hand, the appeal to a superaddressee means a hegemonic intervention in the political discourse. Such an appeal changes the trajectory of discourse, as this ploy can shift the level of political negotiation from seeking compromise in the public sphere to the negotiation of political identities. It would seem that at this point dialogue ceases to work and is frozen into a soliloquy. But if we remember Bakhtin's observation that even monologic utterances have their dialogical moment, then the authoritative character of such utterances is weakened. By the same token, one can say that hegemony as a side in dialogue contradicts itself and takes a part in the polyphonic, multi-voiced nature of the social.

What, then, is the significance of Bakhtin's views for political theory? I think that his ideas allow us to treat society as a place of never-ending dialogue between the utterances (texts) of different social groups. This polyphonic nature of society does not entail that for a society to exist hegemony is necessary. Dialogue and polyphony exist also between monologic utterances and if we refer this principle to society, we have to arrive at the conclusion that a conversation between even arbitrary voices is always possible. On the other hand, no conclusion can close discussion, compromise can always be cast into question, and the reference to instances situated beyond the immediate range of particular discussion (including transcendental and Habermasian quasi-transcendental conditions) becomes an element of this discussion.

I believe that from Bakhtin's concept of dialogue it is possible to develop a new path in political theory showing that the opposition between antagonism and dialogue can be overcome, at least under certain social conditions. This is so because, as I have pointed out earlier, dialogue is inscribed in all social relations and 
even more it is a basis for the constitution of the self. Therefore even in the most oppressive social circumstances we can find elements of dialogical relations in the world in which individuals act. However, they are suppressed by the totalitarian political system, which can be, for the sake of political theory, interpreted as an objectified world of culture. The tension that arises in such a situation between two worlds is reflected also and first of all in language, which can be a vehicle of understanding as well as a mode of oppression and domination. This complicated character of language is described for instance in the context of heteroglossia: "The living utterance, having taken meaning and shape at a particular historical moment in a socially specific environment, cannot fail to brush against thousands of living dialogical threads, woven by socio-ideological consciousness around the given object of an utterance; it cannot fail to become an active participant in social dialogue. ... The way in which the world conceptualizes its object is a complex actall objects, open to dispute as they are with qualifications, are from one side highlighted while from the other side dimmed by heteroglot social opinion, by an alien word about them" (Bakhtin 1981, 276-277). It is nevertheless always possible that "The word, breaking through to its meaning and its own expression across an environment full of alien words and variously evaluating accents, harmonizing with some of the elements in this environment and striking a dissonance with others, is able, in this dialogized process, to shape its own stylistic profile and tone" (Bakhtin 1981, 277). But how is one to activate a latent dialogic tendency that is present in all human relations and in all human utterances? It is a task for the theory of democratic society.

Here we touch upon the second dimension of dialogue, which is the normative one. Dialogue, besides being the necessary condition of comprehension, is also an ethical ideal. I think that it would be very useful for political theory to follow some insights in educational theory where this ethical side of dialogue has already been elaborated. Eugene Matusov writes about dialogue and its predicaments in the following words: "Bakhtin showed that there are two major related pitfalls for establishing the regime of internally persuasive discourse: excessive monologism (in other words, the solitude of the powerful) and excessive dialogism (in other words, the solitude of the powerless)" (Matusov 2007, 221). Both tendencies, though they can be included in dialogical relation, can also become serious distortions of it. In political theory their counterparts would be two extreme dangers for democracy as described in Claude Lefort's theory. In the first case we would be dealing with the filling of "empty space" by certain symbols; in the second case, society is entirely "fragmented." In dialogical categories these two situations show the deficit of true dialogue, which leads to understanding but not necessarily to agreement.

Two strands in contemporary social theory that I identify in this article with the names of Habermas and Mouffe seem to overemphasize the one side of the social and for that reason they were subjected to critique even by their proponents. Rummens, in his article on disambiguating Mouffe's theory, points out that "Democratic conflict is constitutive of the unity of the democratic people, not because the 'people' is defined in opposition to the temporary minority, but rather because the ongoing democratic struggle over the proper interpretation of the core value of the liberal community binds majorities and minorities in a common, historical and open ended project" (Rummens 2009, 386). In the light of my 
reconstruction of Bakhtin's dialogical concept it can be interpreted as a need for a reference to the dialectics between dialogue as a formal characteristic of language and dialogue as a living exchange between individuals or social groups. The first characteristic involves founding such norms and rules as a framework for languagebound dialogue that they can secure arriving at a clear meaning of utterance through a chaos of different voices and contradictory intentions. Such meanings in turn would serve as a vehicle of mutual understanding between conflicting groups.

This postulate can be placed very close to Habermas's idea of "ideal communicative situation" but with some reservations. First, it has been noted that Habermas's discursive ethics neglects the concreteness of human beings, which significantly restricts its scope, because as Axel Honneth notes: "It can hardly be denied that our notion of the moral does not exhaust itself in the concept of equal treatment and reciprocal responsibility, but includes modes of conduct that consist of asymmetrical acts of benevolence, helpfulness, and philanthropy" (Honneth 1995, 316). Bakhtin's approach to dialogue in which the concreteness of individual relationships is confronted with the objectified world of culture can be a point of departure for enriching discursive ethics. To do so, it is necessary to identify the ways in which language can be a framework encompassing individual's decision and choices. Second, democracy is not only about agreement but also about disagreement. Pierre Rosanvallon in his seminal book on counter-democracy states this idea clearly: "The history of real democracies has always involved tension and conflict" (Rosanvallon 2008, 3). He also emphasizes that, "If we wish to comprehend the variety of democratic experiences, we must therefore consider two aspects of the phenomenon: the functions and dysfunctions of electoral representative institutions on the one hand and the organization of distrust on the other. Until now, historians and political theorists have been primarily concerned with the first aspect" (Rosanvallon 2008, 5). Bakhtin's concept of dialogue is the perfect instrument for analyzing this double-face nature of democracy, as it allows us to grasp the complex ways of coming to understanding. It also shows that understanding is not a flat, onelevel process, but it involves the relationships between various levels of the social that influence each other. Understanding achieved at one level can be contradicted at another level, which is what makes democracy such a complicated enterprise. For democracy, thus, what is most important is creating the conditions that would facilitate dialogue at all levels without the hope for arriving at ultimate understanding. From this perspective, understanding, not consensus, is a point of convergence of different contradictory powers that makes up democratic society.

In the last parts of The Master and Margarita, Mikhail Bulgakov, who wrote his novel in the same years that Bakhtin was developing his concept of dialogue, describes the dream of Pontius Pilatus: "And once the procurator lost connection with what surrounded him in reality, he immediately set out on the shining road and went up it straight towards the moon. He even burst out laughing in his sleep from happiness, so wonderful and inimitable did everything come to be on the transparent, pale blue road. He walked in the company of Banga, and beside him walked the wandering philosopher. They were arguing about something very complex and important, and neither of them could refute the other. They did not agree with each other in anything, and that made their argument especially interesting and endless" [my emphasis] (Bulgakov 1997, 796). In Bulgakov's book it is only a 
dream, a utopia, which opposes the brutal reality of Imperial Rome and Stalinist Russia, where any dialogue was suppressed by political power. However this picture corresponds with Bakhtin's idea of dialogue where the most important is to understand the other and not to seek with him or her agreement at any price. Dialogue is a value in itself, but it allows us to order social life and protects it from falling into the monopoly of one group or into the chaos of fragmented voices.

Acknowledgments For suggestions and comments, I thank Martin Jay of the University of California at Berkeley, and two anonymous reviewers. I am also very grateful to Dr. David Schauffler for his remarks and correcting my English grammar.

Open Access This article is distributed under the terms of the Creative Commons Attribution Noncommercial License which permits any noncommercial use, distribution, and reproduction in any medium, provided the original author(s) and source are credited.

\section{References}

Bakhtin, M. M. (1981). Discourse in the novel. In The dialogic imagination. Four essays by M.M. Bakhtin, edited by M. Holquist, translated by C. Emerson and M. Holquist. Austin: University of Texas Press.

Bakhtin, M. M. (1993a). Problems of Dostoyevskyś poetics. Edited and translated by C. Emerson. Minneapolis: University of Minnesota Press.

Bakhtin, M. M. (1993b). Toward a philosophy of the act. Edited by V. Liapunov and M. Holquist, translated by V. Liapunov. Austin: University of Texas Press.

Bakhtin, M. M. (1994). Speech genre \& other late essays. Translated by V. W. McGee, edited by C. Emerson and M. Holquist. Austin: University of Texas.

Bulgakov, M. (1997) The master and margarita. Translated by R. Pevear and L. Volokhonsky. London: Penguin.

Clark, K., \& Holquist, M. (1984). Mikhail Bakhtin. Cambridge: The Belknap Press of Harvard University Press.

Critchley, S., \& Marchart, O. (2004). Introduction. In S. Critchley \& O. Marchart (Eds.), Laclau: A critical reader. London: Routledge.

Eskin, M. (2000). Ethics and dialogue in the works of Levinas, Bakhtin, Mandelshtam, and Celan. Oxford: Oxford University Press.

Flynn, B. (2005). The philosophy of Claude Lefort. Evanston: Northwestern University Press.

Habermas, J. (1987). The theory of communicative action. Volume 2 Lifeworld and system: A critique of functionalist reason. Translated by Th. McCarthy. Boston: Beacon Press.

Habermas, J. (1991). The theory of communicative action. Volume 1 Reason and rationalization of society. Translated by Th. McCarthy. Cambridge: Polity Press.

Hirschkop, K. (1999). Mikhail Bakhtin: An aesthetic for democracy. Oxford: Oxford University Press.

Honneth, A. (1995). The other of justice: Habermas and the ethical challenge of postmodernism. In S. K. White (Ed.), The Cambridge companion to Habermas. Cambridge: Cambridge University Press.

Koczanowicz, L. (1999). The choice of tradition and the tradition of choice: Habermas' and Rorty's interpretation of pragmatism. Philosophy \& Social Criticism, 25(1), 55-70.

Koczanowicz, L. (2000). Freedom and communication: The concept of human self in Mead and Bakhtin. Dialogism. An International Journal of Bakhtin Studies, 4, 54-66 .

Laclau, E., \& Mouffe, C. (1985). Hegemony and socialist strategy: Towards a radical democratic politics. London: Verso.

Makhlin, W. (1993). Commentaries. In V.N. Vološinov, V.N., Freĭdizm. Moskva: Izd-vo "Labirint."

Manent, P. (1998). The city of man. Translated by M. A. LePain. Princeton, NJ: Princeton University Press.

Matusov, E. (2007). Applying Bakhtin scholarship on Discourse in Education: a critical review essay. Educational Theory, 57(2), 215-237.

Mouffe, C. (1999). Introduction: Schmitt's challenge. In C. Mouffe (Ed.), The challenge of Carl Schmitt. London: Verso.

Nielsen, G. (1995). Bakhtin and Habermas. Toward a transcultural ethics. Theory and Society, 24(6), 803-835. 
Rosanvallon, P. (2008). Counter-democracy. Politics in the age of distrust. Translated by A. Goldhammer. Cambridge: Cambridge University Press.

Rummens, S. (2009). Democracy as a non-hegemonic struggle? Disambiguating Chantal Mouffe's agonistic model of politics. Constellations, 16(3).

Smith, A. M. (1998). Laclau and Mouffe. The radical democratic imaginary. London and New York: Routledge.

Taylor, Ch. (2007). Modern social imaginaries. Durham: Duke University Press.

Vološinov, V. N. (1976). Freudianism. A critical sketch. Translated by I. R. Titunik and edited in collaboration with N.H. Bruss. Bloomington and Indianapolis: Indiana University Press.

Leszek Koczanowicz is Professor of Philosophy at The Warsaw School of the Social Sciences and Humanities (Wroclaw Faculty) in Poland. He specializes in political philosophy, social theory, and cultural aspects of politics. His previous appointments include Wroclaw University (1977-1997), Opole University (1997-2002), SUNY/Buffalo (1998-1999 and 2000-2001), and Columbia University (2004-2005) where he was Distinguished Professor at the School of International and Public Affairs. He is the author and editor of seven books and numerous articles in Polish and English, including Community and Emancipations. Discussing Post-Conventional Society, Lower Silesia University Press, Wroclaw, 2005; Politics of Time. Dynamics of Identity in Post-Communist Poland, Berghahn Books, Oxford-New York, 2008. Currently he is working on a book, Non-Consensual Democracy: Dialogue and Critical Community, for the Edinburgh University Press. 